\title{
Sobre a escola na produção da vida em comunidade: experiências ashaninka no rio Amônia
}

\author{
PAULA COLARES
}

UNIVERSIDADE FEDERAL DO OESTE DO PARÁ (UFOPA), SANTARÉM/PA, BRASIL

HTTPS://ORCID.ORG/0000-0002-9276-4053

\section{Introdução}

Este trabalho pretende discutir o papel que a escola desempenha na criação e manutenção da vida em comunidade, nova forma de organização social entre os Ashaninka, que passa a se constituir no rio Amônia no início da década de 1990. As reflexões aqui apresentadas são fruto de um trabalho etnográfico desenvolvido entre 2014 e 2017, em diferentes etapas ${ }^{1}$. Meu trabalho de campo foi marcado pela colaboração, especialmente, de professores ashaninka, no levantamento de informaçóes para auxiliar na elaboração do Projeto Político-Pedagógico (PPP) da escola. Dessa forma, os métodos tradicionais de trabalho de campo se associaram ao processo simultâneo de realização de entrevistas e oficinas com os professores, no sentido de subsidiar a produção deste documento. Para este artigo, o diálogo com os professores e a perspectiva destes sobre os objetivos da escola e o lugar que essa instituição tem hoje na vida coletiva, configura o foco da análise.

"Agora vivemos em comunidade", dizem constantemente os moradores do rio Amônia, em oposição a quando viviam no "tempo dos patrões". Naquele tempo, como me disse Antônio Piyãko, chefe dos Ashaninka, "[se] trabalhava a madeira, vivia em todo canto. Era muito trabalho e não tinha como a gente se juntar [...]. A gente tirava madeira e entregava para o patrão". Busco aqui compreender essa passagem na história ashaninka, tratando de como a escola ganha forma na composição de seus movimentos.

$1 \mathrm{O}$ trabalho de campo realizado contou com financiamento do CNPq e da Faperj. 


\section{Fragmentos de uma história Ashaninka}

Os Ashaninka são falantes de uma língua da família arawak e pertencentes a um conjunto que foi descrito como arawak pré-andino ou arawak sub-andino. Veber (1992: 52) sugere que constituem provavelmente "o maior grupo etno-linguístico na bacia amazônica hoje" e aponta que a população total no Peru, onde se situa a maior parte desses indígenas, corresponde a aproximadamente 90.000 pessoas (2007: 5). Naquele país, vivem nos rios Perené, Tambo, Ene, Pichis, Urubamba e Pachitea, além da área montanhosa de interflúvio dos rios (Rojas, 1997). A estes, somam-se aqueles que migraram para o que hoje se encontra definido como território brasileiro, para viver às margens de rios acrianos, precisamente os rios Amônia e Breu, no Alto Juruá, no município de Marechal Thaumaturgo, e no rio Envira, que tem a cidade de Tarauacá como aquela mais próxima. Assim, no Brasil, encontram-se em sete diferentes Terras Indígenas, todas homologadas ${ }^{2}$. No rio Amônia vive cerca de metade da população total de mais de 1.600 pessoas $^{3}$.

Os Ashaninka fizeram e fazem, ainda hoje, coexistir uma forte autonomia de suas unidades concretas (ainda que também oscilantes), os grupos domésticos ou assentamentos familiares, e uma rede de relações de afinidade extensa, conectadas através, especialmente, do piyarensti, a bebida de mandioca fermentada que funciona como articulador político (Mendes, 1991) entre suas unidades mais ou menos estáveis, e de um sistema de intercâmbio que faz operar redes de relação em níveis e localidades distintas, o ayompari, importante para as relações de troca e a produção de afinidade. Komãyari, professor na Apiwtxa ${ }^{4}$ traduz o termo ayompari $i^{5}$ por "pessoa estranha/ parceiro de negócios", e Killick (2008: 24) define a rede de relações comerciais entre parceiros no sistema ayompari como "a prática de produzir relações formais duradouras entre parceiros de troca (ayompari) de áreas distantes". Para o etnólogo, o piyarentsi e o ayompari funcionam em diferentes escalas, interligando o local ao que está mais distante, conectando indivíduos e grupos familiares e, ao mesmo tempo, possibilitando a autonomia e a independência entre as unidades menores (Id.).

Nas linhas de história que costuram as relações ashaninka, sejam elas conectadas às relações ambivalentes de guerra e comércio com o Império Inca, à circulação do sal e de mercadorias em torno do Cerro de la Sal com outros coletivos Arawak, passando pelas confederações guerreiras que podiam incluir coletivos Pano, e pela resistência junto à figura de Juan Santos Atahualpa (sobre esse capítulo da história ashaninka, ver: Hvalkof \& Veber, 2005; Brown \& Fernandez, 1991), é constante o desejo de buscar relacionar-se com o Outro mantendo níveis distintos de conexão, traçando redes em que algumas de suas unidades - sempre dispersas em núcleos familiares - mantem-se relativamente mais distantes dos fluxos diretos da alteridade mais radical porque outros, com quem tecem relações através

2 São elas: Kampa do Rio Amônia; Kampa do Igarapé Primavera; Kampa e Isolados do Rio Envira; Kaxinawa/Ashaninka do Rio Breu; Kaxinawá do Alto Humaitá; Riozinho do Rio Envira; e Jaminawa/Envira.

3 Informação disponível no site do Instituto Socioambiental (ISA), na parte referente ao povo Ashaninka. https://pib.socioambiental. org/pt/Povo:Ashaninka. Acesso em 26/05/2020.

4 Apiwtxa é o nome da comunidade Ashaninka na TI Kampa do rio Amônia, assim como de sua associação. Define um "nós, juntos”.

5 Segundo Hvalkof e Veber (2005: 228), uma provável origem da palavra ayompari é a termo em espanhol “compadre”, que se transforma em "cumpari" em quéchua antes de chegar à sua forma final 
do sistema tradicional ayompari, aproximam-se de pontos da circulação interétnica. Como descreveu Mendes (1991: 22), a respeito do sistema de intercâmbios tradicional ashaninka, para um tempo muito mais recente, final da década de 1980 e início de 1990:

Os grupos que habitam regiões mais próximas às fazendas trabalham para os patrões e são pagos com mercadorias (era o caso dos Ashaninka do Amônia até recentemente); mas os Ashaninka que se recusam a entrar em contato direto com os brancos, e que habitam regiões mais afastadas, dentro da floresta fechada, conseguem esses manufaturados por meio de seus ayumpari.

Esse sistema fractal de relações (Carneiro da Cunha, 1998), constituído nas relações ashaninka tanto internamente, entre os núcleos familiares e territórios políticos, quanto nas relações com os Outros com quem comercializavam, foi apropriado e modificado estruturalmente pelo sistema de aviamento que sintetizava as relações no empreendimento caucheiro, marcador do início das relações de patronagem naquela região da Amazônia, assim como nas atividades madeireiras que simbolizam, para os Ashaninka do rio Amônia, a concretização do "tempo dos patrões”. Isto porque, como sugere Carneiro da Cunha, "a própria essência da rede de crédito e de produção de caucho" (1998: 10) era a sua distribuição ao longo dos rios e de pontos do sistema de aviamento, mas com uma diferença radical:

[a] saber, aquela que separa um sistema igualitário de um sistema de dominação. Sob o antigo regime, todos os pontos de vista, ao mesmo tempo homólogos e independentes entre si, eram equivalentes: não havia ponto de vista privilegiado sobre o conjunto. Ao contrário, no caso do aviamento, estrutura de ordem, o crédito e a dívida eram transitivos: transmitiam-se entre negociantes, patrões, subpatrões e seringueiros (1998: 10-11).

A economia da borracha se baseava na entrega da produção de caucho ou seringa em troca de créditos que posteriormente seriam convertidos em bens para circular em sentido oposto. Na prática se realizava como um sistema de dívidas que se constituía numa hierarquia entre os grandes patrões da borracha - alguns se tornaram mesmo figuras históricas, como Fitzcarraldo -, aqueles intermediários brancos localizados em diversos pontos entre a floresta e as cidades, e os trabalhadores diretos (Gow, 1991).

A ocupação permanente dos territórios ashaninka no Brasil foi um processo que teve impulso com a indústria caucheira - como consequência das pressões e ameaças de caucheiros peruanos em seus territórios tradicionais, ou pela atração, pelos próprios caucheiros, desses índios para atuar como "guardiões dos seringais" e realizar correrias contra os Amahuaca, índios "brabos” e seus inimigos tradicionais, que viviam no alto e médio curso do Amônia (Pimenta, 2002). Assim, se a presença desse povo no Alto Juruá remonta ao século XVII, foi somente no início do século XX que o lugar passou a ser residência permanente.

Dessa forma, ainda que tenham sido impactados pela economia caucheira, o fato de terem encontrado no alto do rio Amônia um refúgio onde a incidência de árvores seringueiras era diminuta (Mendes, 1991:18), permitiu certo distanciamento tanto dos caucheiros peruanos quanto dos seringa- 
listas e seringueiros brasileiros, ao mesmo tempo em que possibilitou a manutenção relativa do modo de vida tradicional.

Num período posterior, na década de 70, as relações semi-escravistas de aviamento, num mesmo sistema englobante de patrões, se materializaram para atingir diretamente os Ashaninka do rio Amônia, com a chegada da frente madeireira naquela região. Em meados da década de 1980, com a introdução de maquinários capazes de devastar rapidamente uma extensa área (Pimenta, 2007), o território ashaninka foi profundamente afetado, e, consequentemente, também foram as condições de vida daquele povo. Essa década é marcada, simultaneamente, pela emergência de movimentos indígenas e de seringueiros, especialmente do encontro entre a União das Nações Indígenas (UNI) e do Conselho Nacional de Seringueiros (CNS), que fez florescer no Acre, terra de Chico Mendes recém-assassinado, uma Aliança dos Povos da Floresta. É então nesse contexto, no estado do Acre, que crescem relações inesperadas entre índios, seringueiros, organizações indigenistas e ambientalistas, relações estas que propiciaram a criação de novos possíveis, como as reservas extrativistas, as cooperativas indígenas e as escolas diferenciadas.

Existem quatro acontecimentos que ressoam em conjunto e se apresentam como eventos de coletivização, e que atuaram como uma força centrípeta que aproximou as famílias dispersas para a vida em comunidade. Foram eles: a criação de uma cooperativa, que permitiu a obtenção de mercadorias sem a figura do patrão; a escola, que atraiu as famílias que desejavam obter acesso aos conhecimentos "dos brancos"; a mudança de famílias que viviam ao longo do Igarapé Amoninha para a entrada do território, no rio Amônia, como estratégia de defesa contra invasores; e, por último, a conquista da demarcação da terra, que produziu um território limitado, porém de posse coletiva. Nesse sentido, a vida em comunidade reflete as iniciativas ashaninka para viver autonomamente sem submeterem-se a patrões brancos. Desta maneira, o que acontece na comunidade ashaninka guarda muitas semelhanças com o processo de criação de escolas e Comunidades Nativas no Peru, conforme detalhado por Gow (1991), Killick (2005) e Sarmiento (2011). Neste trabalho, o foco será a escola na construção do que os moradores do Amônia descrevem como a sua comunidade.

\section{A escola como força de atração}

Deve-se ressaltar, primeiramente, a singularidade dos Ashaninka do Amônia em relação à realidade da educação escolar para indígenas no Brasil, já que a escola, oficialmente, aparece no rio Amônia apenas na década de 1990, como "escola diferenciada".

Peter Gow (1991) descreveu o lugar da escola no pensamento e nos movimentos dos Piro, abrindo caminho para o interesse da etnologia pelas apropriações indígenas dessa instituição. Assim como no caso dos Ashaninka com quem se desenvolveu a pesquisa que embasa este artigo, Comunidades Nativas no Peru (o equivalente legal a Terra Indígena no Brasil), constituem-se imbricadas a uma escola, veículo de conhecimentos "civilizados" cuja apreensão tem a potência de impedir a escravização pelos brancos e, por isso, permitir que os índios mantenham e defendam suas redes de parentesco. 
No caso dos Ashaninka do rio Amônia, a aproximação das famílias antes dispersas ao longo do rio se deu através da escola, que funcionou como uma força de atração e de permanência ao redor de sua órbita. Como me explicou Komãyari, um dos mais antigos professores da Apiwtxa e filho de Claudio e Eriwira:

Antes de eu ser aluno, os meus pais também viviam nos seus cantos, assim, isolados, com poucos contatos. Só tinha contato quando tinha caiçuma, e era difícil. E esse contato entre crianças também era difícil. Mas depois da demarcação da Terra, começaram a se juntar mais perto. Mas assim mesmo, juntando perto, muita gente não conseguia segurar as famílias. Conversava, fazia reunião, mas só juntava quando tinha caiçumada ${ }^{6}$, festa, naquele momento. Mas quando terminava iam pros seus cantos, ficava vazio.

Mas com a existência da escola eu vi muita mudança. Quando chegou a escola, começaram as famílias a se juntar. Quem vivia mais distante teve que morar mais perto, para seus filhos irem para a escola, porque dificultava muitos os seus filhos virem de muito longe.

[...] Tem muita família que falava: ter uma escola, porque quem tinha escola só eram os brancos, só o não indígena, só tinha escola era na cidade. Então por isso quando chegou a escola na comunidade, todo mundo ia em cima para conhecer a escola. Todo mundo queria acessar as aulas. Então por diversos motivos a escola atraiu as famílias, as pessoas. Então por isso a escola é muito importante. Além de ela ser uma referência, ela tem um significado muito forte, ele atrai as pessoas, ela tem uma coisa muito bonita e todo mundo quer - todo mundo quer ter. [...] muitas famílias falavam muito, meus pais, meus avós, que não tinham muito contato com a escola, ouviam que existia a escola, essa tal (entrevista, Apiwtxa, 2015).

Nas etnografias recentes produzidas sobre o povo Ashaninka, especialmente no Peru, o processo de criação das "Comunidades Nativas" e o lugar central da escola nesses movimentos, com suas implicações nas dinâmicas territoriais e políticas, vem sendo objeto de reflexão, especialmente a partir do caminho trilhado pelo trabalho de Peter Gow. Por exemplo, a tese de Sarmiento (2011), desdobra os sentidos do "viver bem" para os ashaninka, constatando que no Baixo Urubamba hoje, viver bem depende do viver junto, como uma comunidade capaz de se defender coletivamente de relações de exploração ${ }^{7}$; Killick (2005) sugere que, no rio Ene, o desejo de que seus filhos frequentassem a escola foi também a motivação central para a vida em comunidade.

A criação de escolas é mobilizada, em alguns lugares, para a formação de novas aldeias, quando a construção de prédios escolares e os cargos assalariados produzidos através dela funcionam como força de dispersão. Entre os Ashaninka, no entanto, a escola produziu em torno de si a comunidade. Gow (1991: 248) define que, para os Piro vivendo no Baixo Urubamba, "a escola, ao lado do status legal de

\footnotetext{
6 Caiçumadas são os eventos que reúnem diferentes núcleos familiares para consumir caiçuma, a bebida fermentada de mandioca. São espaços privilegiados de interação entre as parentelas e de produção da socialidade ashaninka. Na língua asheninka, tanto o evento quanto a bebida são chamados de piyarensti.

7 Sarmiento discute, a respeito dos Ashaninka da região do baixo Urubamba, no Peru, o conceito nativo de kametsa asaiki/ viver bem, que se associa ao controle das emoções e afetos destrutivos, assim como à prática das emoções e afetos produtivos, na constituição da "pessoa Ashaninka de verdade" (2011:104). Sua pesquisa está centrada em compreender como os Ashaninka elaboram a noção de viver bem e o manejo das relações vivendo junto em "comunidades".
} 
Comunidade Nativa é o maior símbolo da existência da comunidade e o evento principal de sua fundação", e sugiro o mesmo para o caso dos Ashaninka no rio Amônia.

Os autores que produziram etnografias junto aos Ashaninka no Peru oferecem chaves de entendimento da relação entre a produção de escolas, comunidades e pessoas (individuais e coletivas). Suas conclusões nos permitem também observar, por contraste, como a política indigenista nos dois países - Peru e Brasil - e a construção legal dos territórios - a saber "Comunidade Nativa” no caso do primeiro e "Terra Indígena" no caso do segundo - combinou-se com as formas sociais ashaninka. Pimenta (2002) apresenta uma breve imagem comparativa entre a escola na Apiwtxa e a existente entre os vizinhos também Ashaninka na Comunidade Nativa de Sawawo, no Peru. Segundo o antropólogo, o objetivo da escola em Sawawo é o de "transformar os índios em cidadãos peruanos através do aprendizado da língua espanhola" (Pimenta, 2002: 290). Uma das distinções centrais entre os dois modelos de escola ${ }^{8}$, sugere Pimenta, é que na Apiwtxa todos os professores são indígenas e são parte da comunidade. Já em Sawawo as aulas são ministradas por professores não indígenas designados pelo governo, e que na maioria das vezes pensam sobre si mesmos como desbravadores à frente de um projeto civilizador (Pimenta, 2011: 108).

No rio Amônia, os Ashaninka seguiram um modelo de "educação diferenciada" que conheceram com as experiências de formação na ONG Comissão Pró-Índio do Acre (CPI/AC) $)^{9}$ e que foi tornado política oficial posteriormente, ainda que com muitas transformações e distorções em seu processo de implementação. Diferentemente do que observou Pimenta ${ }^{10}$ do lado peruano da fronteira, onde:

Em Sawawo, a partir dos 6 anos de idade, as crianças cantavam diariamente o hino nacional, homenageando a bandeira, içada permanentemente na aldeia. $\mathrm{O}$ material didático fornecido pelo Ministério da Educação do Peru anunciava de forma explícita que o principal objetivo da escola era formar patriotas. Em capas, cadernos e livros escolares expunham claramente os símbolos da nação: escudo, bandeira e hino nacional (Pimenta, 2002: 109).

No rio Amônia não havia experiências formais de escola entre os Ashaninka antes dos anos 1990. No relatório que Seeger e Vogel (1978) escreveram a respeito dos Ashaninka no rio Amônia, para a Funai, fizeram referência à presença de cartilhas do Movimento Brasileiro de Alfabetização (Mobral) em algumas casas e se perguntaram sobre os possíveis efeitos desse material. Esses antropólogos perceberam o desejo de muitos por aprender português e matemática para impedir a exploração pelos patrões (1978: 50). Afirmaram, no entanto, a inexistência de escolas, apontando que apenas quatro moradores frequentavam, no Remanso, comunidade não indígena no rio Bagé, um curso de alfabetização com um

8 Silvia Tinoco (2006) desenvolve em sua tese de doutorado uma comparação também muito interessante entre dois modelos de escola na fronteira, dessa vez entre a Guiana Francesa e o estado do Amapá, na Amazônia brasileira. Nesse trabalho, a antropóloga explora as diferenças entre a escola dos Wajãpi no Brasil, estruturada como a dos Ashaninka em um modelo de escola diferenciada em diálogo com ONGs, e nas Guianas, onde a educação é pensada como a formação de cidadãos franceses.

9 ONG responsável por um programa alternativo, depois oficializado, de formação de professores indígenas e escolas "diferenciadas".

10 A pesquisa de Pimenta, realizada no início dos anos 2000, descreve uma realidade que, da publicação de sua tese (em 2002) para cá, se transformou expressivamente. As políticas de educação escolar indígena no Peru se aproximam cada vez mais do modelo de "educação diferenciada" no Brasil, com a formação de professores indígenas e os adjetivos "intercultural" e "bilíngue". 
professor do Mobral. Entre eles estavam Cláudio e sua esposa Eriwira, que, apesar de não terem nesta época aprendido a ler e escrever, são dos maiores entusiastas da escola na comunidade hoje, e seus filhos são agora maioria entre os professores.

No início da década de 1990, Isaac - um dos filhos do chefe Antônio Piyãko e de uma mulher filha de posseiros na região, Piti $^{11}$-, que havia feito o Ensino Fundamental numa escola em Cruzeiro do Sul, a cidade "grande" mais próxima do Alto Juruá, foi escolhido para ser o primeiro professor na escola que então se desenhava. Com a mediação da antropóloga Margareth Mendes, a primeira a desenvolver pesquisa no Amônia, os Ashaninka produziram uma ortografia da língua com o linguista Wilmar D'Angelis. Logo em seguida, Isaac começou a participar do Projeto "Uma Experiência de Autoria” da Comissão Pró-Índio do Acre ${ }^{12}$. É um momento particular, pós-Constituição de 1988, em que se começa a esquadrinhar uma política de formação de professores indígenas e de criação de escolas “diferenciadas" sob gestão do Estado. No caso do Acre, a CPI/AC iniciou esse projeto no início dos anos 1980, como uma oposição radical ao modelo até então oferecido para os povos indígenas, modelo esse centrado na ideia de "civilização" e "integração" dos índios.

Certamente, como chamou atenção Peter Gow (1991), as tentativas, por parte do Estado, de civilizar os índios encontram, entre os nativos, uma contrapartida semântica do que significa civilizar-se. Trata-se de um equívoco entre duas conceituações a partir de pontos de vista distintos. O antropólogo define para o caso dos Piro o que aparece também nas etnografias sobre os Ashaninka vizinhos a eles no Peru: "Ser 'civilizado' é ser autônomo, é ser capaz de viver em comunidades de acordo com os valores próprios das pessoas nativas, e não sob os desejos caprichosos de um patrão" (1991: 2). Gow aponta que esses valores nativos podem ser resumidos na ideia de "viver bem", que significa, especialmente, comer "comida de verdade", produzida da articulação do trabalho de homens e mulheres, e coabitar em comunidades pacíficas que cultivam suas relações através do idioma do parentesco. Para isso, a criação de comunidades e da escola, seu motor de atração. Como espaço propício para a aquisição de conhecimentos civilizados, a escola possibilita a apreensão de ferramentas que lhes permitem impedir que se retorne à vida do tempo sob o jugo dos patrões, que era também um tempo em que as pessoas não sabiam se defender.

Os Ashaninka me diziam constantemente que um dos principais motivos para quererem a escola para seus filhos e netos é para que eles não sejam humilhados na cidade, para que saibam se comunicar no posto de saúde, para calcular o troco e para falar com os brancos que passam períodos na aldeia. Os mais velhos dizem que era por não entenderem o português que eles eram explorados pelos patrões. "Eles não sabiam se defender", diziam os Ashaninka do Gran Pajonal para Killick (2005: 197), referindo-se aos seus antepassados. O mesmo me disse Moisés, liderança e xamã Ashaninka:

11 O casamento de Antônio e Piti foi o primeiro casamento interétnico no rio Amônia e relações desse tipo continuam hoje quase exclusivamente em sua família, já que alguns de seus descendentes também se casaram com pessoas não ashaninka. Essa relação tem um papel que não pode ser menosprezado na atual constituição da comunidade Apiwtxa, questão que exploro num capítulo de minha tese de doutorado (Colares, 2019). Para outras referências aos efeitos políticos desse encontro, ver Pimenta (2018).

12 O projeto "Uma experiência de autoria" desenvolvido pela CPI/AC, iniciou-se em 1983, a partir de demandas formuladas inicialmente por lideranças Kaxinawá (Huni Kuin), expandindo-se logo para incorporar a formação de professores e pesquisadores indígenas de outras etnias no Acre. Teve como base, em seu início, a capacitação de indígenas para atuar à frente de cooperativas e projetos de autossustentação econômica. Os Ashaninka passaram a fazer parte dessa formação somente em 1993. 
O surgimento da escola foi uma necessidade que veio do contato com o mundo do não índio. Mesmo na época dos patrões, uma das nossas maiores dificuldades, uma das maiores explorações, vinha de as pessoas não conhecerem contabilidade. Então um patrão chegava e trocava um isqueiro por uma árvore de mogno. Pra gente era um grande valor: um isqueiro pode te dar comida, dar fogo. Então a gente tinha consciência da importância daquilo pra gente. Mas o lado do patrão, que conhecia essas coisas, era de má fé, porque sabia que uma árvore de mogno comprava milhões de isqueiros. Então em cima de toda essa exploração que a gente vinha sofrendo, a gente conseguiu buscar a escola, depois da demarcação da Terra, pra que a comunidade pudesse ter um pouco dessa noção e começasse a se defender (entrevista, Apiwtxa, 2014).

Essa questão aparece no relatório de Seeger e Vogel (1978) também como a motivação para as famílias que queriam apreender os códigos do mundo dos brancos. "São explorados no seu trabalho e nas suas transações comerciais porque ignoram o sistema de valores que nos rege" (1978: 49), notam em sua visita. Os dois antropólogos descrevem exemplos similares ao da troca do isqueiro por uma árvore de mogno relatado por Moisés, como o de: “[u]m roçado de 50 paneiros de farinha [que] custou ao patrão um quilo de açúcar, outro de sal e uma garrafa de querosene" (Id.).

Para os Ashaninka que vivem no rio Amônia, a escola aparece como um veículo que os permite viver como uma comunidade de famílias autônomas ao invés de grupos dispersos trabalhando para os madeireiros, mas mantidos por eles em relações de servidão. Assim como para os Piro, a educação escolar se tornou o vetor de um movimento que impede a sujeição e a escravização. No caso da Apiwtxa, no entanto, a tônica de criação e manutenção da comunidade e da escola é focada num discurso de fortalecimento da "cultura tradicional"13.

A cultura como meio de relação com os brancos é fruto de uma criação ashaninka a partir do diálogo com os primeiros indigenistas que trabalharam com eles, e se seguiu com a parceria com a Comissão Pró-Índio do Acre, na formação de professores. Antônio Macedo, então funcionário da Funai, e figura de destacada importância no indigenismo acriano, afirma (em entrevista para o antropólogo José Pimenta) que o seu trabalho no rio Amônia foi de "conscientização":

Eu chegava aqui e eles diziam que eram pobres. Eu trazia um pedaço de tabaco para fumar e eles pediam tudo dizendo que eram pobres [...] aí comecei a explicar para eles o conceito de riqueza, capital e dizer pra eles que eles não eram pobres porque as terras onde eles moravam eram ricas e eles é que não estavam sabendo como desenvolver-se aqui dentro da terra onde eles viviam. Aí foram se conscientizando, se conscientizando. [...] esses meninos [os filhos mais velhos de Antônio e Piti] eram pequenos, mas não me deixavam quieto. [...] tinham uma fome de aprender muito grande. [...] eles perguntavam muitas coisas, eles perguntavam tudo. Aí eles foram crescendo, crescendo e eu explicava para eles que não adiantava eles crescerem sozinhos e se tornar uma elite pura e simples, o meu trabalho não ia ter valor. $\mathrm{O}$ meu trabalho só ia ter valor se eles conseguissem trazer ao povo deles todo esse crescimento. Por isso é que você chega aqui e vê essa aldeia organi-

13 A questão da emergência da "cultura" como idioma das relações interétnicas e seus efeitos internos é tratada no último capítulo de minha tese de doutorado (Colares, 2019). Para uma excelente discussão sobre as apropriações indígenas da "cultura” no Acre, com foco nos Huni Kuin do rio Humaitá, conferir Weber (2006). 
zada do jeito que está aqui. Antes, não era assim, eram casas dispersas, não tinha essa coordenação de esforços e pensamentos" (Pimenta, 2002: 152).

Assim, o que deve ser ressaltado não é a transformação ditada pelos indigenistas, mas o modo através do qual os Ashaninka passam a mobilizar, na relação com os brancos, não mais o idioma, por exemplo, da pobreza (que certamente era também induzido para gerar efeitos relacionais), mas outro viés utilizando um novo léxico, o do tradicionalismo e da "cultura”. Isaac Piyãko explica como, também na criação da cooperativa, estava presente além da busca pela autonomia econômica, um processo de "revitalização" e valorização do tradicional:

[...] a política de valorização também já existia [antes da criação da escola], porque a cooperativa foi criada nesse sentido. Como iríamos trabalhar os produtos? Madeira ninguém trabalhava mais, carne [de caça pra vender] ninguém ia trabalhar mais, então a única alternativa era a cultura, ver o que a gente tinha ali de conhecimento tradicional, pra poder trabalhar. Uma das alternativas foi o artesanato. E aí na época a Margarete [Mendes, antropóloga], quem iniciou mesmo foi o Terri [Aquino] e o [Antônio] Macedo e disseram: "na situação mesmo de vocês, pra vocês se libertarem, a cooperativa é um caminho”, e nos ajudaram, Macedo e Terri, a criar uma organização. Quando a Margarete chega já tínhamos essa política, então ela entra para estruturar melhor a produção. [...] Então ela ajudou a valorizar isso e o artesanato foi feito a partir de uma pesquisa do que a gente tinha no passado, o que tinha no presente e o que podia melhorar. Então a partir dessa pesquisa, fomos encontrando as peças de artesanato e foi sendo trabalhada essa valorização da cultura, da língua, da vestimenta. Naquela época ninguém usava muito a cushma [vestimenta tradicional] mais. Pouca gente... Meu pai mesmo não usava mais. Quem usava mesmo éramos nós, os filhos da mãe [de dona Piti]. Mas o papai por conta da influência dos brancos não usava mais, porque era uma forma dele se livrar do preconceito. Muitas famílias não usavam mais cushma, mas quando a gente começa a valorização, começam a voltar a usar também. Isso foi muito forte (entrevista, Apiwtxa, 2014).

Como nos ensina Isaac, a escola dá seguimento a uma "política cultural" iniciada no encontro das lideranças (então jovens) com agentes da Funai e a antropóloga Margareth Mendes. Esses sujeitos, especialmente Francisco, Moisés e Isaac, os filhos mais velhos de Piti e Antônio, tiveram um papel ativo nas transformações da socialidade ashaninka, conduzindo eventos que promoveram mudanças e novas possibilidades de relação entre as famílias e entre os Ashaninka e os brancos.

No processo de se fazer como coletivo Ashaninka, reduzindo a totalidade do território a uma Terra Indígena, produzindo uma comunidade que integra os diferentes grupos familiares autônomos num único nampitsi - que Mendes (1991) traduz por "território político" -, os moradores do rio Amônia passaram a se perceber como um conjunto sob liderança de um chefe e seus filhos. Essas lideranças são reconhecidas como tal porque dão continuidade ao modelo do sistema de famílias independentes que se organizam ao redor do chefe de um grupo doméstico, sem que as diferenças se dissolvam numa coisa só. Assim, as famílias que desejam viver em assentamentos mais afastados do núcleo da aldeia conseguem, através da comunidade - da escola e da cooperativa -, manter um fluxo de bens e relações à distância, permitindo aos moradores da Apiwtxa fortalecer suas unidades autônomas através 
de um manejo de suas relações com o exterior, entendendo-se agora como parte de um coletivo, uma comunidade.

\section{Caminhos para uma outra escola indígena}

Com o surgimento do movimento indígena e de organizações de apoio aos índios nas décadas de 1970 e 1980, aconteceu uma reformulação das possibilidades oferecidas pela instituição escolar, com a proposta de escolas alternativas ao modelo assimilacionista que era então oficial, partindo-se do pressuposto de que a escola poderia oferecer aos povos indígenas meios de conhecer e dominar ferramentas do mundo dos brancos, para então superar relações de desigualdade e opressão. As primeiras experiências de escolas "diferenciadas", pensadas como parte de um conjunto de lutas por autonomia e território, aconteceram do encontro de ONGs pró-índio com grupos indígenas, como no caso da Comissão Pró-Índio do Acre com os Huni Kuin ou do Centro de Trabalho Indigenista com os Wajãpi, no Amapá. No caso da CPI/AC, o diálogo entre a organização indigenista e os Huni Kuin estendeu-se para outros povos da mesma região, compondo um projeto de formação de professores e de gestão de escolas que promoveu a relação entre diversos grupos indígenas do estado do Acre, que passaram a se encontrar anualmente nos cursos realizados pela ONG.

Nos anos 1970, quando a Funai chegou ao Acre, o encontro dos povos indígenas com as frentes de exploração e expansão econômica datava de quase um século e suas consequências haviam produzido no imaginário não indígena local a percepção de que ali não havia mais índios, apenas "caboclos", sujeitos em processo de transformação e assimilação. Grande parte dos grupos indígenas havia sido sedentarizada em colocações de seringal, e vivia no entorno de patrões para quem trabalhavam sob o regime de escravidão por dívidas. Mesmo após a decadência da borracha, novas frentes de exploração foram postas em jogo, e naquele momento havia um incentivo e uma inclinação à promoção da pecuária nas terras onde viviam grupos indígenas, além da expansão, apontada anteriormente para o caso dos Ashaninka, da frente madeireira.

Alguns estudantes e militantes acrianos, que nesse tempo começavam a se aproximar dos coletivos indígenas, passaram a viajar e produzir relatórios com o objetivo de qualificar o trabalho da recém-chegada Funai. O antropólogo Terri Aquino visitou naquele momento algumas aldeias Huni Kuin e, enquanto realizava pesquisas, levantou dados sobre a situação em que viviam os índios, apontando para as relações de exploração às quais estavam submetidos.

Para Monte (2008), coordenadora do projeto de educação da CPI/Acre, é aí que se encontra o germe dessa instituição pró-índio, que surge para atuar politicamente na transformação do contexto apontado por essas experiências de pesquisa. Depois de Aquino, outras duas pessoas, estimuladas por ele, passaram a produzir, em 1978, relatórios de viagens que são ao mesmo tempo pesquisas de campo e o início de uma parceria fundada numa perspectiva de construção de relações menos desiguais e de alternativas de reconstrução de autonomia para os povos indígenas nas florestas acrianas. Essas viagens centravam-se, sobretudo, no apoio logístico e prático à viabilização de cooperativas como meio de for- 
çar o fim do monopólio dos patrões sobre os bens industrializados e garantir algum controle dos índios nas transações, inclusive na venda da borracha que produziam como "índios seringueiros".

O projeto das cooperativas indígenas foi basilar no início das políticas indigenistas no Acre, e esteve associado às lutas pelo reconhecimento do direito dos povos indígenas ao território. A CPI surgiu em 1979 imbuída de um espírito de militância política pró-índio que vinha tomando forma no Brasil, e produzindo um diálogo entre as universidades, especialmente entre os antropólogos, de um lado, e o movimento indígena em construção, de outro. Assim, a CPI se empenhou em apoiar as lutas indígenas e buscou intervir numa realidade que previa o fim dos povos indígenas naquele estado. $\mathrm{O}$ projeto das cooperativas, no entanto, apontou os desafios para a sua implementação, uma vez que se fazia necessário habilitar os índios a gerirem suas cooperativas e controlarem comunitariamente sua economia. O programa de educação da CPI partiu dessa demanda pela formação de quadros internos para tornar possível a manutenção das cooperativas, e se delineou a partir dos primeiros relatórios escritos pelos fundadores da ONG. A ideia que norteia seu rascunho é profundamente influenciada pela educação popular e as propostas de Paulo Freire, para quem a educação deveria ser uma prática coletiva de libertação.

Além da necessidade do português e da matemática instrumentais, para uma utilização prática na gestão de cooperativas, percebeu-se que as relações com os patrões haviam deixado marcas entranhadas não só nos corpos - como aqueles que marcavam a fogo a pele de "seus" trabalhadores - mas também na autoestima daqueles sujeitos. Assim, se libertar dos patrões não era apenas uma questão de separar-se deles fisicamente, mas de impedir a continuação dos efeitos de sua dominação.

Em 1983, a partir da identificação desses problemas e da demanda de lideranças Kaxinawá, a CPI organizou o primeiro curso de formação de "monitores indígenas". A formação de monitores, que posteriormente se torna a de professores indígenas, aconteceu de 1983 a 2000, compreendendo assim um período de intensas transformações não só nas políticas de educação para os povos indígenas no Brasil, mas também da construção de um campo de direitos específicos para os índios.

Não se pode esquecer que desde os tempos em que esta terra era colônia de Portugal, as tentativas de conversão - religiosa e civilizatória - não cessaram, ainda que tenham ganhado novas roupagens. Com o Serviço de Proteção ao Índio (SPI), criado em 1916, se qualifica uma atuação para o Estado republicano na "proteção" dos índios, que significava concretamente a liberação de seus territórios para as frentes de exploração e a incorporação dos indígenas como "trabalhadores nacionais" através de uma reeducação promovida pela escola e pelo trabalho. A "localização de trabalhadores nacionais", que completou o nome do SPI nos seus primeiros anos - Serviço de Proteção aos Índios e Localização de Trabalhadores Nacionais (SPILTN) -, manteve-se como projeto nem sempre declarado, mas atuante. Nesse projeto, a escola desempenhou papel importantíssimo.

A iconografia desse período mostra as crianças vestidas uniformemente, sentadas em cadeiras dispostas em fileiras, voltadas para o professor ou professora não indígenas, repousados ao lado da bandeira brasileira. As vozes que ecoam nos relatos contam dos castigos físicos, da rígida disciplina, da proibição do uso das línguas indígenas. Com o objetivo expresso de moldar a uma só identidade a sociedade brasileira, que deveria também falar uma só língua, o SPI criou diversas escolas onde instau- 
rou seus Postos Indígenas, para assim "amansar", "atrair”, "pacificar” e "integrar” os índios. Quando, em 1967, poucos anos após o Golpe Civil-Militar de 1964, a Funai é criada para substituir, como órgão tutor dos índios, o SPI, em meio a denúncias de violações de direitos, de corrupção e escravização dos indígenas, as prerrogativas que orientam as ações e concepções com relação aos povos indígenas se mantêm, mas acontecem mudanças nas formas da relação. A educação missionária, que era oficialmente rejeitada pelo SPI, de cunho mais militarista e nacionalista, nunca deixou de estar presente por meio de experiências como a dos internatos salesianos no Alto Rio Negro, que conviveram e ultrapassaram em duração a existência dos Postos Indígenas.

No entanto, é com a criação da Funai que ganha força a educação missionária como modelo de ação do Estado, que, seguindo a emergência de um discurso em defesa da educação bilingue que se impõe naquele momento, passa a adotar convênios com organizações como o Summer Institute of Linguistics (SIL), que mascara até os dias de hoje o proselitismo religioso que é seu objetivo, com um discurso que busca apresentar sua metodologia como científica, voltada à pesquisa sobre as línguas indígenas. O SIL geriu oficialmente diversas escolas indígenas em toda a América do Sul, incluso o Brasil. Uma mudança expressiva nesse cenário, nacionalmente, viria apenas na década de 1990.

No caso do Acre, antes mesmo de 1988 (marco da nova Constituição), em 1985, a CPI assinou um convênio com a Funai e a Secretaria de Educação do Acre (SEE/AC), para a formação de professores indígenas e gestão das políticas educacionais para esse público. Através desse convênio, se tornou possível, já naquela época, a inclusão desses professores índios e suas escolas no sistema estadual de ensino. O objetivo da CPI, afirma Monte (2000), era o de que esta experiência e suas concepções políticas e pedagógicas, fossem adotadas como modelo para uma política pública, o que de fato aconteceu nas décadas seguintes. A partir do reconhecimento dos povos indígenas como sujeitos de direitos coletivos diferenciados, com a Constituição Federal de 1988, toda a proposta da política pública de educação escolar indígena hoje em vigor, se produz inspirada nas propostas até então alternativas, como a da CPI/AC, em contraposição ao modelo integracionista, adotando os adjetivos "diferenciada", "específica", "bilingue" e "intercultural".

\section{A escola para organizar a vida em comunidade}

Em 1992, ano da homologação da Terra Indígena Kampa do Rio Amônia, as famílias construíram no Igarapé Amoninha, onde vivia a maior parte dos Ashaninka, uma casa pequena, coberta de palha e assoalho de paxiúba, como são as casas tradicionais, e Isaac, que havia ido estudar na cidade, começou a ser professor pouco depois, com mediação da CPI. A necessidade de uma escola se devia ao contexto de transformações nas relações com os brancos e à criação da cooperativa, surgida um ano antes para retirar dos patrões o controle da circulação de bens manufaturados, impedindo a manutenção das relações de exploração a que estavam submetidos. Com a cooperativa, necessitavam aprender a administrá-la. A escola recém-criada atraiu mais famílias para a órbita de Antônio Piyãko, acelerando o processo de formação e organização de uma comunidade que havia se iniciado com a cooperativa. Segundo Isaac: 
Quando a gente começa a escola o sentido era organizar a comunidade. Antes da escola a gente já tinha organizado, porque a cooperativa tinha esse sentido de unir o pessoal e se libertar da mão dos patrões e dali começar a tirar os patrões e trabalhar a autonomia. Então antes da escola já havia uma organização por parte da comunidade. Quando a escola entra já tinha uma organização política interna, então a escola entra pra complementar (entrevista, Apiwtxa, 2014).

O professor Komãyari define assim o início do projeto da escola:

O primeiro objetivo da escola veio do pensamento das lideranças. A gente já tinha o território demarcado, limitado, então a gente tinha a necessidade de um administrador da cooperativa, tinha que ter uma pessoa para dominar a escrita e a leitura, escrever documentos, assinar papéis. Qual era o pensamento das lideranças? Era capacitar os jovens para que futuramente eles fossem responsáveis nessa parte de documentação, ler ofícios, anotar as coisas da cooperativa, pagar os fornecedores dos produtos. Esse era o objetivo da escola na época. E outro pensamento quando se iniciou a escola era o de capacitar jovens para serem lideranças, lideranças formadas também no conhecimento não indígena, ter uma visão do contexto mundial e ter uma visão política bilíngue, com domínio do português e do asheninka. O maior desafio era aprender a falar português. A comunidade criou a escola, com professores para responderem, dar conta dessa parte, da obrigação de articular e organizar para capacitar futuras lideranças ou pessoas que pudessem contribuir na comunidade (entrevista, Apiwtxa, 2014).

Para realizar o que a comunidade havia decidido, foi feito o contato, através das lideranças, com a Comissão Pró-Índio do Acre, que desenvolvia o projeto de formação de professores indígenas ao qual me referi, há quase 10 anos. Naquele momento, Terri Aquino e Antônio Macedo, dois dos fundadores da ONG, já haviam travado há alguns anos relações de amizade e aliança com a família de Antônio Piyãko. A CPI enviou a assessora Sandra Machado para ajudar no início da escola e em 1993 o professor Isaac começou a participar dos cursos de formação. No relatório que elaborou sobre essa primeira viagem, a assessora da CPI descreveu assim o que encontrou:

A organização Ashaninka é espantosa, naquela região vemos o verdadeiro conceito de 'comunidade. Um exemplo disso é a questão da escola: quando cheguei lá, pensei que teria de reunir a comunidade, discutir quem seria o professor, como seria a escola, discutir a educação que queriam etc. Porém, tudo isso já tinha sido pensado por eles, já tinham escolhido o professor, como seriam as aulas, o calendário, o local da escola, enfim, tudo já estava resolvido, e só esperavam por mim para 'oficializar' suas decisões (Relatório de viagem de 1992, da assessora Sandra Machado apud Monte, 2008:104).

Em 1995, os Ashaninka realizaram a mudança da aldeia para a ponta da terra indígena, às margens do rio Amônia, com o objetivo de fiscalizar e impedir a invasão da TI pelos brancos. Nessa mudança, a escola também foi do igarapé Amoninha para a atual aldeia. Nos anos seguintes, novos professores juntaram-se a Isaac para atender a demanda crescente dos alunos. 
Depois de estruturada a comunidade, e ao longo do processo de formação dos professores nos cursos da Comissão Pró-Índio, os Ashaninka foram ampliando os sentidos que construíam para a escola. O "tempo dos patrões", que se encerrava com a construção de uma comunidade autônoma, marcou a vida dos Ashaninka no rio Amônia e teve impactos diversos na vida das famílias. Então como explica Wewito, professor e liderança:

A comunidade discutiu junto o que seria, para nós, a escola, que aluno nós queríamos formar e pra quê nós queríamos formar. Pra competir com o mercado fora ou para prepará-los para sobreviver dentro desse território com os seus conhecimentos, para fortalecer seus conhecimentos, fortalecer sua cultura e colocar em prática aquilo que é da cultura que também é ensinamento e é importante para nós? Tudo isso foi discutido e a gente começou a ver que aquelas coisas que estavam sendo esquecidas, mas que não estavam perdidas, eram nossas e precisavam ser trazidas de volta. Antes não tínhamos a liberdade de fazer nossas festas tradicionais porque os brancos proibiam ou chegavam e acabavam com as festas. Quando conseguimos nosso território, passamos a ter a liberdade de fazer isso. Então a escola foi junto, conversando com cada aluno, explicando a importância disso, porque é importante para nós ter nossa cultura e nossos conhecimentos, tanto da confecção dos nossos artesanatos, da nossa medicina, da nossa cura, das nossas histórias, dos nossos mitos. Para nós a escola é um conhecimento, mas o nosso conhecimento tradicional, na oralidade e na prática, é como uma universidade que estava ali sem ter uma organização de seus ensinamentos, pra que a gente pudesse tomar um rumo. Não temos que tornar tudo isso uma coisa "da escola", mas é importante mantermos esses conhecimentos, que são conhecimentos milenares que vem sendo repassados pelo nosso povo e que nós temos que dar continuidade. $\mathrm{E}$ a gente discutia muito com outros professores indígenas [do Acre], era a maior das nossas discussões com outros professores. Muitos deles não queriam a educação tradicional, ou seja, a educação do povo, queriam uma educação que viesse de fora (entrevista, Apiwtxa, 2014).

Também o professor Komãyari aponta a emergência da "cultura" na escola, afirmando seu sentido para além, apenas, do acesso a conhecimentos dos brancos:

Hoje a gente pensa que [o objetivo da escola] não é só capacitar futuras lideranças, ou administradores de cooperativa e associação, pessoas que possam ler e assinar documentos. Além disso, temos que registrar e ampliar a educação para defender o interesse, o direito da comunidade, o que a comunidade precisa. Nós precisamos registrar nossos conhecimentos, nossa cultura, nós precisamos ter material didático, nós precisamos construir sem depender de alguém que vem de fora que vai dizer que nós temos que fazer assim. A escola tem que ser independente pra que a gente possa aprender mais, ter mais conhecimento e mais professores para atender a comunidade. A gente tem que pesquisar o que está se perdendo. E aprender o português não é só aprender a ler e escrever, pra isso tem que ler muito, interpretar a história (entrevista, Apiwtxa, 2014).

Nesse sentido, é importante apontar a reflexão, por parte dos professores ashaninka, e diversas vezes ressaltadas a mim por Isaac, de que a escola deve fortalecer os conhecimentos tradicionais sem escolarizá-los, encontrando meios de, na educação escolar, não os transformar em conteúdos escolares 
dissociados da vida concreta. Para isso, esses professores entendem que o fortalecimento dos conhecimentos tradicionais depende da sua continuidade nas relações familiares fora do espaço escolar. É nesse sentido que eles experimentam com as "aulas práticas", sobre as quais tratarei em seguida.

\section{A escola contra a "desabilitação" na vida familiar}

Desde o início da escola, como sugere uma primeira tentativa de construção de um Projeto Político-Pedagógico desenvolvida junto aos assessores da CPI no final dos anos 1990, as aulas acontecem presencialmente, com professor e alunos, quatro dias por semana: segunda, terça, quinta e sexta. As quartas-feiras são contabilizadas como dias letivos, inclusas no planejamento escolar como "aulas práticas", quando os filhos acompanham os pais durante todo o dia em suas atividades cotidianas, aprendendo junto deles a observar e se situar no ambiente. A presença dos alunos junto de seus pais deve-se também à importância que as crianças têm na vida produtiva da família. Assim explica Alzelina, hoje professora na aldeia:

Eu vejo assim: é importante [a manutenção das quartas como dia de aula prática] porque uma criança da cidade, ela não sabe nem cozinhar, lavar uma roupa, cuidar de outra criança. E as crianças aqui da aldeia são muito diferentes, porque desde os cinco anos ela sabe lavar uma roupa, fazer uma comida, fazer um fogo, cuidar do próprio irmãozinho dentro de casa quando a mãe deixa. É muito importante o dia de quarta-feira, ela acompanha os pais. As meninas acompanham as mães, né? A mãe ensina a cozinhar, lavar uma roupa, limpar um terreiro, tomar conta de casa. E os meninos aprendem com o pai a pescar, caçar, cuidar do roçado. E a gente como pais precisa muito deles também. Se eles ficarem os cinco dias na escola, a gente não tem nem como conviver com eles, nem ensinar eles também (Alzelina, oficina realizada na Apiwtxa, 2015).

Isaac, então diretor da escola, na mesma oficina em que Alzelina compartilhou essa sua perspectiva, complementou a professora apontando que na Apiwtxa, diferente do que acontece com os brancos, não existe um "sistema de empregado", e que as crianças são componente indispensável na economia doméstica.

Laura Rival (1997), a partir de suas pesquisas na Amazônia equatoriana, afirma que nas aldeias escolarizadas dos Huaorani, acontece um processo de "desabilitação" das crianças para a vida na floresta, já que, na descrição dessa autora, se produz uma separação entre adultos - pais de família - produtivos, e crianças que deixaram de acompanhar seus pais nas atividades cotidianas para frequentar as salas de aula, onde aprendem conhecimentos que os distinguem dos adultos. Entre as famílias Ashaninka, parece existir uma resistência ativa a essa desabilitação, e os moradores da Apiwtxa apontam enfaticamente que as crianças “aprendem na escola, mas aprendem com os pais também”, e que ambos os conhecimentos são complementares.

A escola funciona, através da organização das aulas práticas e das reuniões comunitárias sempre convocadas e conduzidas por professores e lideranças, como uma espécie de observatório de todas as parentelas que compõem a comunidade, pois a partir dos alunos, os professores olham também os pais 
e o que acontece nos núcleos familiares. A descrição da coordenadora pedagógica da escola Samuel Piyãko ${ }^{14}$, de como as quartas-feiras compõem o planejamento escolar, nos dá indícios disso:

As atividades das quartas-feiras, quando não tem aula dentro da escola, é pros filhos acompanharem os pais nas atividades do cotidiano, nos roçados, nas pescarias. É muito importante, mas eu vejo que isso precisa estar definido mesmo. Tem que ser definido pelo professor no dia anterior, o professor tem que orientar o aluno, dizer para ele para perguntar pro pai, ou pra mãe o que eles vão fazer na quarta-feira, se vai ser uma caçada, se vai pro roçado. O professor tem que dar essas orientações, para o aluno ter aquele compromisso mesmo de ir acompanhar o pai. Porque tem aquele que tem uma preguicinha né? O pai vai pro roçado, ou vai pescar, e o filho fica em casa só brincando, jogando bola, jogando pião. Então essas orientações do professor, obrigando mesmo ele a ir, quer dizer assim, quase obrigando, a acompanhar essa atividade, é muito importante. E também não só orientar, mas depois, no dia seguinte, perguntar: "você foi pra onde? O que você aprendeu? Vamos compartilhar com os outros colegas e cada um vai falar o que foi que fez na quarta-feira durante o dia todo". Com a conversa informal e depois sistematizar também, junto com o professor, «vamos escrever agora um texto», [e assim] pode desenvolver várias atividades dentro daquele planejamento. Isso tem que ser definido como compromisso dos professores (Fátima, oficina realizada na Apiwtxa, 2015).

No cotidiano da escola, as aulas práticas e a participação das crianças nas atividades familiares dão o tom para a dinâmica das demais atividades escolares, para além das quartas-feiras. Uma pedagogia que se constrói por meio de "atividades", perceptível no cotidiano escolar, pode trazer luz a essa questão.

A cópia exaustiva de textos é apontada tanto por Collet (2007) quanto por Weber (2006) como característica da metodologia escolar, respectivamente, dos Bakairi e dos Huni Kuin. Em ambos os casos, as autoras apontam a aproximação desse método, dissonante das propostas "diferenciadas" para as escolas indígenas (inspiradas nas ideias da educação popular), dos processos nativos de ensino e aprendizagem, onde a observação e a repetição são a base da apreensão de uma nova habilidade. $\mathrm{Na}$ escola Samuel Piyãko - escola da Apiwtxa -, no entanto, a cópia de textos a partir de livros didáticos é inexistente.

O mais comum, principalmente entre os professores mais jovens, é que a duração das aulas seja quase toda tomada por "atividades", sempre escritas pelo professor no quadro, sem muitas orientações, seguidas pela realização individual pelos alunos, finalizadas pela correção do professor. Aulas expositivas não fazem parte da forma de ensinar dos professores, excetuando-se em partes os professores mais antigos ainda atuando, Komãyari e Wewito, que se utilizam de exemplos e referências da vida na aldeia para explicar os exercícios propostos. Minha hipótese é que esta forma de ensinar por atividades é também similar às formas tradicionais de ensino e aprendizagem entre os Ashaninka.

Explico: quando pequena a criança acompanha seus pais e a sua exposição ao ambiente possibilita que ela, ativamente, apreenda o mundo que a rodeia e as relações que constituem seu universo.

14 Samuel Piyãko, que dá nome à escola na Apiwtxa, foi um dos primeiros Ashaninka a fazer residência permanente no rio Amônia, no início dos anos 1930. Era xamã e se mostrou hábil na interlocução com os brancos, tornando-se o primeiro "chefe" dos Ashaninka ali, quando da chegada da Funai ao Acre. Depois de sua morte, seu filho Antônio o substituiu. 
Os pais oferecem pouca orientação verbal, e à medida que a criança demonstra interesse e capacidade para conduzir por conta própria tarefas da vida cotidiana, seus familiares a mandam, sem instruções, fazer por conta própria. Assim, a autonomia é produto do empenho da criança em aprender, devendo os pais atuar incentivando e garantindo a imersão da criança nos espaços variados, seja o roçado, a caiçumada, a casa ou a floresta. Aprendizagem silenciosa (Beysen, 2008), aprendizagem informal (Weiss, 2005), ou educação onde a criança deve "aprender por ela mesma" (Lenaerts, 2004: 179), fato é que, na pedagogia ashaninka, "[u]ma criança depende fortemente da observação dos adultos e das lições de sua experiência pessoal" (Weiss, 1974: 392) para apreender o mundo.

Essa observação é articulada a uma produção própria num processo de reprodução que não exclui a criação. O papel dos pais é criar os filhos corretamente e prepará-los para serem autônomos em uma nova unidade familiar, propiciando para eles os contextos para que desenvolvam suas habilidades, e o dos filhos é ativamente tornar-se agente, um ser humano produtivo. Por isso Hatã, morador da Apiwtxa, explica, sobre a educação fora da escola: "Eu levo desde pequenininho meu filho pro roçado, que é para ele andar, pra ele olhar, participar, aí ele vai aprendendo". Assim, ele continua: "Quando está desse tamanhozinho [ainda bem pequeno], ele não sabe plantar ainda, mas ele pode andar no roçado, acompanhar, brincar lá. Aí quando fica maior eu chamo. Como o meu outro filho, que já tem 10 anos, esse daí já sabe plantar, já sabe cavar um barro pra plantar” (entrevista na Apiwtxa, 2014).

$\mathrm{Na}$ escola, os professores também não oferecem conteúdos para serem absorvidos simplesmente pelas crianças. Tratam de mediar o seu processo de "leitura do mundo", como dizia Paulo Freire (2005), testando suas habilidades e conhecimentos e introduzindo a escrita e a leitura a partir daquilo que rodeia a criança. A rotina escolar se produz desta forma: o professor inicia a aula escrevendo no quadro uma atividade, um exercício, a ser realizado quase sempre individualmente pela criança. Depois, os alunos levam os cadernos até a mesa do professor, que avalia assim a capacidade da criança de desenvolver o que lhe foi solicitado, ou corrige no quadro, com pouca participação dos estudantes. Algumas vezes, os alunos são convocados a compartilhar o que escreveram para a atividade, mas nunca são repreendidos pelo professor pela leitura quase sempre inaudível que acontece nesses momentos.

Especialmente nos primeiros anos do Ensino Fundamental, as crianças são estimuladas a desenhar, a partir da orientação do professor, o que fazem com seus pais e a vida na comunidade. As atividades para casa, quando existem para os mais velhos, costumam basear-se no registro, pelo aluno, de conhecimentos de seus familiares: histórias para serem buscadas com os avós, plantas que a família cultiva, o que fizeram no final de semana. Também as atividades de matemática, por exemplo, consistem em cálculos a partir dos produtos da cooperativa ou da produção dos roçados para a merenda escolar. Assim, a escola é um teste da vida em comunidade, um observatório das famílias, uma produção contínua dos laços que unem todas as parentelas a partir das crianças que se reúnem na escola. Daí emergem, do empenho da criança no universo letrado e na disposição para atuar para a comunidade, aquelas que futuramente atuarão como professores, agentes de saúde, agentes agroflorestais ou lideranças.

Diferentemente do processo que acompanha a escolarização em muitas aldeias indígenas, onde a escola é vista pelas famílias como ponte para o trabalho na cidade, entre os Ashaninka, como afirmou para mim Wiko, barqueiro da escola, "as crianças aprendem na comunidade para trabalhar na comu- 
nidade”. Não por coincidência, são poucos os casos de migração para a cidade, restritos hoje a alguns membros das famílias de lideranças. Komãyari analisa assim a escolarização para as crianças e jovens no rio Amônia:

É uma comparação que eu faço: uma escolinha de futebol, um timezinho que vai começar a formar uma equipe, ele vai treinar, vai aprender, conhecer as regras e até mesmo ter habilidade no futebol, na bola. Aí depois ele vai aperfeiçoar, mas não são todos desse time, os que estão treinando, não é todo mundo que vai aprender, ou seja, não é todo mundo que vai ter a mesma habilidade, o mesmo desenvolvimento. Vão ter diferenças. Um vai se interessar mais, um que tem mais habilidade, pode se interessar em jogar lá fora. Com a escola é a mesma coisa: ela leva um grupo de pessoas, comparando com a turma de alunos em sala de aula, todos os alunos, vamos dizer que tem uns 50 alunos numa sala. Esses 50 alunos não vão todos se formar, outros vão ficar no meio do caminho e o outro vai terminar o Ensino Fundamental. Aí vai diminuindo. Pode ser que todo mundo termine o Ensino Fundamental, mas daí depois no Ensino Médio vai diminuir, outros vão fazer outras atividades, podem se casar, construir família e não se interessar mais por estudar. Aí depois chega o momento de terminar o Ensino Médio e depois chega fazer faculdade. Esses que terminaram o Médio, uns poucos vão fazer faculdade. Então o conhecimento é assim (Komãyari, entrevista, Apiwtxa, 2015).

\section{Considerações finais}

A escola indígena funciona no encontro entre pessoas, coletivos, saberes e epistemologias, como um "espaço de fronteira", para utilizarmos a definição de Tassinari (2001), ou como "encruzilhada", como define Luciano (2013). A escola remete, sobretudo, a tensões e negociações políticas, como lugar de reconstrução de mundos em transformação. Como propõe Silvia Tinoco (2007: 256), ela é primordialmente um "laboratório político", no qual se experimentam ideias sobre os outros e sobre si mesmos.

Ainda que apropriada pelos Ashaninka para viver em comunidade, a escola está sempre imersa numa tensão entre algo que promove sua autonomia, mas também como algo que pode representar uma ameaça se não for adequadamente controlada:

Para a gente é muito bom [a existência da escola], porque a gente garante esse lado de não ser mais explorado da forma que a gente era antes. Mas também a escola desperta muito um lado não indígena. É importante marcar um limite. A nossa educação aqui não é para o mundo de fora. Lá tem um milhão de doutores, pessoas formadas e lá segue. A gente tem que se voltar para a nossa cultura, os nossos costumes. É por isso que a gente tem a escola diferenciada, para voltar os estudos para dentro da cultura. Por exemplo no ashaninka como primeira língua e só depois o português. É importante trabalhar dentro da cultura e, também, fazer a adaptação da educação lá de fora para um formato que não venha prejudicar a cultura, que venha fortalecer a cultura e fazer as pessoas entenderem porque tantas comunidades foram exterminadas, exploradas, entenderem também a nossa história, trazer isso tudo para o presente, para fazer as pessoas enxergarem a cultura como a pátria delas. (Moisés, entrevista. Apiwtxa, 2014). 
A escola continua a ser vista como espaço de desconstrução de assimetrias e produção de relações controladas com os brancos. Especialmente para os moradores mais velhos, que viveram concretamente as amarras do tempo dos patrões, a escola deve ser capaz de evitar que o desconhecimento da língua portuguesa, da matemática e da escrita se mantenha nas gerações mais novas, para que os Ashaninka possam se comunicar, em contextos específicos, com os brancos. Como sugerem as entrevistas realizadas com os moradores mais velhos, a questão é que a impossibilidade da comunicação produz situações de humilhação, como sugere Ririta, irmã de Antônio Piyãko, referindo-se aos casos de consultas médicas na cidade: "A mulherada aí vai na cidade e perguntam: 'diz aí, esse menino, o quê que esse menino tem?' E ela só abaixa a cabeça, nem fala nada (Ririta, entrevista, 2015). Ou ainda Aricêmio, seu marido: "Aprender português na escola é bom. Tem que aprender essa coisa. Para quando vai andar por aí, porque quando chegar na cidade ele não vai poder saber porque não vai poder falar. E não vai entender o que o branco está falando" (Aricêmio, entrevista, 2015).

Como espaço de fronteira, a escola indígena permite aos Ashaninka um maior controle sobre a agência dos brancos. Desse modo, ela funciona como um espaço de reflexão sobre as transformações em seu mundo e mesmo sobre o mundo dos brancos, num sentido que lembra a incorporação de objetos estrangeiros descrita por Van Velthem (2002) para o caso dos Wayana, que procuram domesticar para então incorporar a alteridade. A escola é importante porque permite a manutenção das relações de parentesco, já os conhecimentos de fora, "civilizados" como sugerem os Piro para Gow (1991), impedem a perpetuação das relações de escravidão, isto é, permitem impedir os fluxos de retorno a um "tempo dos patrões". Mas esses mesmos conhecimentos e as relações que eles evocam são uma ameaça, uma potência de perigo para a vida como Ashaninka. Isaac descreve essas armadilhas que a escola representa:

[...] hoje é uma guerra, pode ser uma guerra silenciosa, a escola. Ela pode destruir um povo sem
que ele esteja percebendo que está sendo destruído por ela. Se a gente não souber usar a escola, a
escrita, a gente pode estar perdido nesse caminho. Pode se perder e pode tirar a identidade de um
povo, o conhecimento. Aí está: contaminar - porque eu acho que aí traz o ponto mais forte -, de
contaminar o cérebro do ser humano, que pensa diferente do outro (Pianta, 2003: s/p).

Ao mesmo tempo, como me disse certa vez, na Apiwtxa, o professor Komãyari, "a escola tem uma direção política também, de articulação, de ordenamento das famílias. Ela tem uma ligação forte com o professor, com o aluno, com a família”. Nesse sentido, a escola cria um contexto de produção efetiva da consubstancialização das crianças e jovens da comunidade, e por extensão, dos seus familiares, que por sua vez participam juntos de reunióes e atividades mediadas pela escola. Manter-se em comunidade hoje é um meio de viver bem, sem o controle dos patrões, e a escola é um dos pontos centrais da produção contínua do "corpo" da comunidade, que precisa ser a todo tempo fabricado.

A escola se faz importante para os Ashaninka porque através dela se mantém o movimento de uma comunidade. E é através da forma comunidade que se pode hoje viver "como Ashaninka", organizados em famílias autônomas. Como definiu Seu Cláudio: 
Tem gente que fala que aquele que estuda mais vai sair fora, vai trabalhar, não sei o que. Aqui pensa outra coisa. Esse é o pensamento de outras tribos. Por exemplo Jaminawa, Kaxinawa, não sei o quê. Em Brasília, tem Xavante, né? Xavante é outra tribo. Eles deixam as aldeias e vão pra cidade. Mas nós aqui não. Eu falo sempre isso. Aqui nós [somos] diferentes de outro povo. Aqui é outro, aqui é o Ashaninka. Nunca vai perder cultura, costume, né? Porque isso é nosso. [...] [Ashaninka] é diferente de outro povo. Tem pessoas [de outras comunidades] que estão pedindo comida na rua, estão morrendo de fome. Rapaz, tem aldeia lá. Por que deixou a aldeia? Na aldeia é melhor porque lá pode mariscar, comer tranquilo, né? Fazer roçado que é pra comer (entrevista, Apiwtxa, 2015).

Paula Colares é Doutora em Antropologia Social pelo Museu Nacional/Universidade Federal do Rio de Janeiro (MN/UFRJ) e professora da Universidade Federal do Oeste do Pará (Ufopa).

\section{REFERÊNCIAS}

Beysen, P. M. B. I. (2008). Kitarense: pessoa, arte e estilo de vida Ashaninka do Oeste Amazônico (Tese de doutorado). Programa de Pós-Graduação em Sociologia e Antropologia, Universidade Federal do Rio de Janeiro, Rio de Janeiro.

Brown, M. F., \& Fernández, E. (1991). War of Shadows: the struggle for utopia in the Peruvian Amazon. Berkeley: University of California.

Carneiro da Cunha, M. (1998). Pontos de vista sobre a floresta amazônica: xamanismo e tradução. Mana, 4(1), 7-22. https://doi.org/10.1590/S0104-93131998000100001

Colares, P. (2019). Viver em comunidade, experimentar com a escola: os Ashaninka do rio Amônia (Tese de doutorado). Programa de Pós-Graduação em Antropologia Social, Museu Nacional, Universidade Federal do Rio de Janeiro, Rio de Janeiro.

Collet, C. L. G. (2007). Escuela bakairi: disciplina, desarrollo y patriotismo. In S.M. García, \& M. Paladino (ed). Educación escolar indigena. Investigaciones antropológicas en Brasil y Argentina (pp. 147-162). Buenos Aires: Antropofagia.

Freire, P. (2005). Pedagogia do oprimido. Rio de Janeiro: Paz e Terra.

Gow, P. (1991). Of Mixed Blood. Kinship and History in Peruvian Amazonia. Oxford: Clarendon.

Hvalkof, S., \& Veber, H. (2005). Los Asheninka del Gran Pajonal. In F. Santos-Granero, \& F. Barclay (ed.). Guía Etnográfica de la Alta Amazonía, v.5 (pp. 75-279). Balboa: Smithsonian Tropical Research Institute; Lima: Instituto Francés de Estudios Andinos. 
Killick, E. (2005). Living Apart: separation and sociality amongst the Ashéninka of Peruvian Amazonia (Tese de doutorado). University of London, London.

Killick, E. (2008). Creating Community: Land Titling, Education and Settlement Formation amongst the Ashéninka of Peruvian Amazonia. Journal of Latin American and Caribbean Anthropology, 13(1), 22-47. https://doi.org/10.1111/j.1548-7180.2008.00003.x

Lenaerts, M. (2004). Anthropologie des Indiens Ashéninka d'Amazonie. Nos soeurs Manioc et l'étranger Jaguar. Paris: L'Harmattan.

Luciano, G. J. dos S. (2013). Educação para o manejo do mundo: entre a escola ideal e a escola real no Alto Rio Negro. Rio de Janeiro: Contracapa/Laced.

Mendes, M. K. (1991). Etnografia preliminar dos Ashaninka da Amazônia brasileira (Dissertação de mestrado). Instituto de Filosofia e Ciências Humanas, Universidade Estadual de Campinas, Campinas.

Monte, N. L. (2000). Os outros, quem somos? Formação de professores indígenas e identidades interculturais. Cadernos de Pesquisa, 110, 7-29. https://doi.org/10.1590/S0100-15742000000300001

Monte, N. L. (2008). Cronistas em viagem e educação indigena. Belo Horizonte: Autêntica.

Pianta, I. da S. (2003). Autonomia, para a gente, é ter uma escola com nosso próprio pensamento. http://www.indiosonline.net/autonomia_para_a_gente_e_ter_uma_escola_/.Acesso em 16 nov. 2020.

Pimenta, J. (2002). "Índio não é todo igual": a construção ashaninka da história e da politica interétnica (Tese de Doutorado). Departamento de Antropologia, Universidade Brasília, Brasília.

Pimenta, J. (2007). Indigenismo e ambientalismo na Amazônia ocidental: a propósito dos Ashaninka do rio Amônia. Revista de Antropologia, 50(2), 633-681. https://www.revistas.usp.br/ra/article/ view/27274

Pimenta, J. (2011). “Parentes diferentes”: etnicidade e nacionalidade entre os Ashaninka na fronteira Brasil-Peru. Anuário Antropológico, 1, 91-119. https://doi.org/10.4000/aa.270

Pimenta, J. (2018). Amor rebelde: história, casamento e política no Alto Juruá. Mana, 24(2), 199 234. https://doi.org/10.1590/1678-49442018v24n2p199

Rival, L. (1997). Modernity and Politics of Identity in na Amazonian Society". Bull. Latin Am. Res., 16(2), 137-151. https://doi.org/10.1111/j.1470-9856.1997.tb00047.x 
Rojas, Z. E. (1997). Origen y clasificación de las plantas cultivadas en el pensamiento mítico asháninka. Anthropologica del Departamento de Ciencias Sociales, 15(15), 255-288. Disponível em: http://revistas.pucp.edu.pe/index.php/anthropologica/article/view/1219

Sarmiento Barletti, J. P. (2011). Kametsa Asaiki: the porsuit of the 'good life' in an Ashaninka village (Peruvian Amazonia) (Tese de doutorado). University of St. Andrews, St. Andrews.

Seeger, A., \& Vogel, A. (1978). Kamparia: breve notícia etnográfica. In Relatório de Viagem no Alto Juruá, município de Cruzeiro do Sul, estado do Acre. Brasília: Fundação Nacional do Índio. Disponível em: https://acervo.socioambiental.org/sites/default/files/documents/0MD00174.pdf

Tassinari, A. M. I. (2001). Escola Indígena: novos horizontes teóricos, novas fronteiras da educação. In A. Lopes da Silva, \& M.K. Leal Ferreira (orgs.). Antropologia, História e Educação: a questão indígena e a escola (pp. 44-70). São Paulo: Global.

Tinoco, S. L. M. (2006). Ekolya et Karetajar: maître de l'école, maître de l'écriture. L'incorporation de l'écriture et de l'école par les amérindiens wayäpi de l'Amapari (Brésil) et de l'Oyapock (Guyane française) (Tese de doutorado). École des Hautes Etudes en Sciences Sociales, Paris.

Tinoco, S. L. M. (2007). Cuando la antropología se encuentra com la educación: la escuela como objeto antropológico de investigación de campo. In S. M. García \& M. Paladino (ed.). Educación escolar indigena. Investigaciones antropológicas en Brasil y Argentina (pp. 241-256). Buenos Aires: Antropofagia.

Van Velthem, L. H. (2002). "Feito por inimigos". Os brancos e seus bens nas representações Wayana do contato. In B. Albert, \& A. R. Ramos (ed). Pacificando o branco: cosmologias do contato no Norte-Amazônico (pp. 61-83). São Paulo: UNESP/Imprensa Oficial do Estado.

Veber, H. (1992). Why Indians Wear Clothes: Managing Identity Across an Ethnic Boundary. Ethnos, 57(1-2), 51-60. https://doi.org/10.1080/00141844.1992.9981445

Veber, H. (2007). Memories, identity, and indigenous/national subjectivity in eastern Peru. Dialogos latino-americanos, 12, 80-102.

Weber, I. (2006). Um copo de cultura: os Huni Kuin (Kaxinawá) do rio Humaitá e a escola. Rio Branco: Edufac.

Weiss, G. (1974). Campa Organization. American Ethnologist, 1(2), 379-403. https://doi. org/10.1525/ae.1974.1.2.02a00110

Weiss, G. (2005). Los Campa Ribereños. In F. Santos-Granero, \& F. Barclay. (ed). Guia Etnográfica de la Alta Amazonía, v. 5 (pp. 1-7). Balboa: Smithsonian Tropical Research Institute; Lima: Instituto Francés de Estudios Andinos. 
Resumo: Este artigo, desenvolvido a partir de um trabalho etnográfico junto aos Ashaninka do rio Amônia, trata do lugar da escola na produção contínua da "vida em comunidade", novidade recente nas dinâmicas da socialidade ashaninka, e que se opõe diretamente ao seu passado imediatamente anterior, quando se vivia no "tempo dos patróes". Busco apresentar o papel que a escola desempenhou na atração dos núcleos familiares e a maneira como as mantém na "Apiwtxa”, traduzível por "nós juntos", que dá nome tanto à comunidade, quanto à associação indígena. Afirmo que viver em comunidade, em torno de uma escola, se traduz na produção de uma força que pretende impedir ativamente o retorno à exploração pelos patrões e, portanto, um meio de reconstruir sua autonomia.

Palavras-chave: escola; comunidade; Ashaninka.

\title{
THE ROLE OF THE SCHOOL IN THE PRODUCTION OF COMMUNITY LIFE: ASHANINKA EXPERIENCES IN THE AMMONIA RIVER
}

\begin{abstract}
This article, based on ethnographic work with the Ashaninka of the Ammonia river, deals with the place of the school in the continuous production of "community life", a novelty in the dynamics of Ashaninka sociality, which is directly opposed to its recent past when they lived in the "time of the bosses." I seek to present the role that the school played in attracting the different families and households and the way it maintains them in the "Apiwtxa," translatable by "us together," which gives name to both the community and the indigenous association. I claim that living in a community around a school translates into the production of a force that intends to actively prevent the bosses from returning and, therefore, it is a means of rebuilding their autonomy.
\end{abstract}

Keywords: school; community; Ashaninka.

RECEBIDO: $29 / 05 / 2020$

APROVADO: $08 / 01 / 2021$ 